\title{
The opinions of specialists and students regarding the use of visual and written expression forms in rhinoplasty education
}

\author{
Sefa Ersan KAYA ${ }^{1, *}$, Özgür KEMAL ${ }^{2}$, Sevgi SOYLU KOYUNCU ${ }^{3}$ KO$^{\bullet}$ \\ ${ }^{1}$ Department of Graphic Design, Turhal Vocational School, Gaziosmanpaşa University, Tokat, Turkey \\ ${ }^{2}$ Department of Otolaryngology, Faculty of Medicine, Ondokuz Mayıs University, Samsun, Turkey \\ ${ }^{3}$ Department of Fine Arts Education, Faculty of Education, Ondokuz Mayıs University, Samsun, Turkey
}

\begin{abstract}
$\begin{array}{llll}\text { Received: } 05.04 .2021 \quad \bullet \quad \text { Accepted/Published Online: 20.04.2021 } & \text { Final Version: } 23.04 .2021\end{array}$
Abstract

This research was conducted to investigate the contribution of visual and written expression to nasal surgery education and the preferences of usage. The research was conducted with the observation of cases in the Ear, Nose and Throat (ENT) Surgery Department of Ondokuz Mayis University Medical Faculty. During the study, the processes of the 'closed dorsum rhinoplasty' cases were observed. The case illustrations made as a result of the observations were presented to the study population comprising 36 medical students from 3 different universities (Ondokuz Mayıs University, Hitit University, İstanbul Medeniyet University). Data were obtained concerning the sampling of the research, the specialization areas of the participants, title groups, number of participants, and the information from the Likert type responses and the nonparametric statistical findings. The results showed that although the use of illustrations was seen to be more important according to the opinion of specialists and non-specialists in the area, sole use was concluded to be insufficient. A total of 43 of 60 ENT specialists and 9 of 11 Plastic Surgery specialists preferred the use of illustrations, photographs and written expression together. Non-specialists were seen to be undecided about their responses while no significant difference was found between specialists. The preferences of the participants were determined to be illustration, photography and written expression, respectively. The results of this study indicate that the use of visual and written expression forms together when they are available is related to the quality of surgery education at a semantic level.
\end{abstract}

Keywords: rhinoplasty, nasal surgical procedures, education, medical illustration

\section{Introduction}

The field of medicine is known to have the three main missions of education, healthcare service and scientific research (Songur, 2016). Medical education has no phase at which visual materials are not used. The rapid increase of information in this field has led to a requirement for the use of new illustrations in educational and scientific areas. The use of focused visual tools, such as the illustrations created for this study, has begun to attract attention as an effective and time-efficient tool that can provide a complete overview of a surgical procedure and lay the groundwork for expedited achievement of surgical competence (Crawshaw et al., 2016). It is important that illustrations are both new and of good quality. For an impressive illustration to demonstrate procedures, the methods used by medical illustrators utilizing their talents and expressive ideas can be categorized as 7 different methods: hovering technique; hidden anatomy, ghosted views, or transparency; centrally focused perspective; action techniques to give life to the procedure; use of insets to highlight one part of the drawing; human proportionality using hands or known objects to show relative size; and stepby-step educational process to depict the stages of a procedure (Mavroudis et al., 2020).
The aim of this study was to investigate the contribution of visual and written elements to rhinoplasty education and the usage preferences. The preferability of the visual expression forms among themselves and their advantages were investigated. This study also aimed to determine the effect of medical illustrations on rhinoplasty education during the course of general medicine.

\section{Materials and methods}

This study is based on the education of surgeons to perform dorsum preservation rhinoplasty. Approval for the study was granted by the Ethics Committee Ondokuz Mayıs University Medical Faculty. A dorsal preservation rhinoplasty operation performed by a senior ENT surgeon was photographed by a medical illustrator. Then the surgeon and the illustrator prepared three descriptive education papers. The first was written only and described the surgery step-by-step. The second paper included step-by-step photographs taken during the surgery. The third paper comprised medical illustrations drawn by an expert medical illustrator.

These three descriptive papers were prepared and then given to the participants in the sequence of first written 
papers, second photographs, and third illustrations. These visual and written expression materials were then presented together (Fig. 1-40). These visuals prepared for the case process were presented to the participants both as (a-

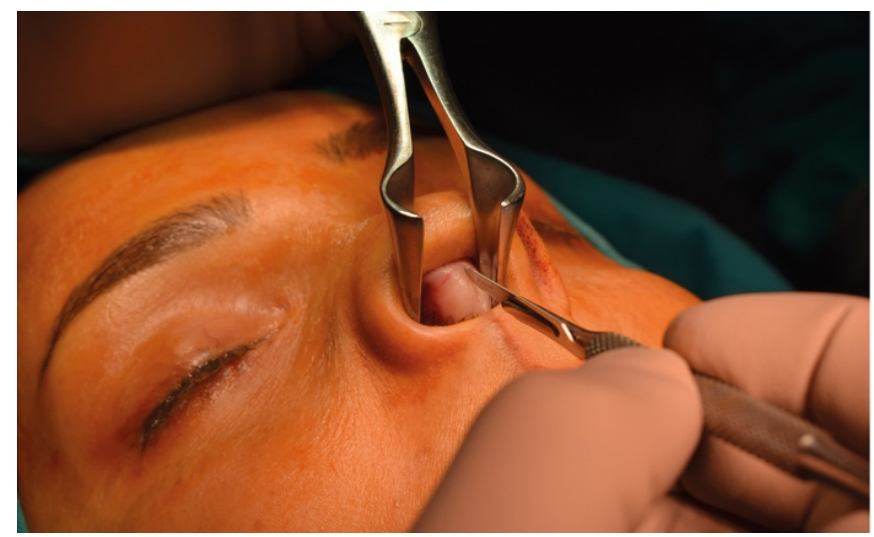

Fig. 1. In closed dorsum-sparing surgery, surgery is initiated by marginal septal incision from the caudal end of the septum. Photographic image of the case process

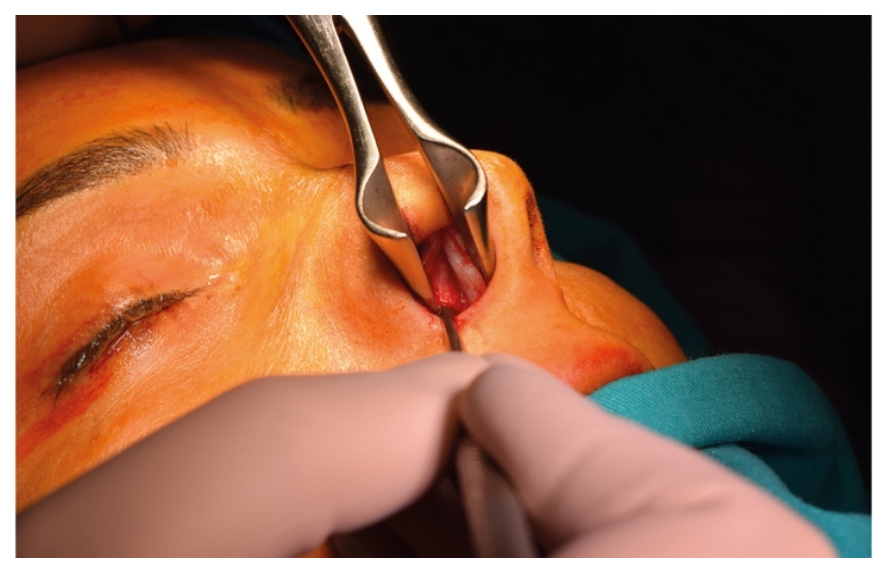

Fig. 3. The incision is remowed from the perichondrium and deepened until cartilage is seen. The nasal speculum is used to visualize the incision site. Photographic image of the case process

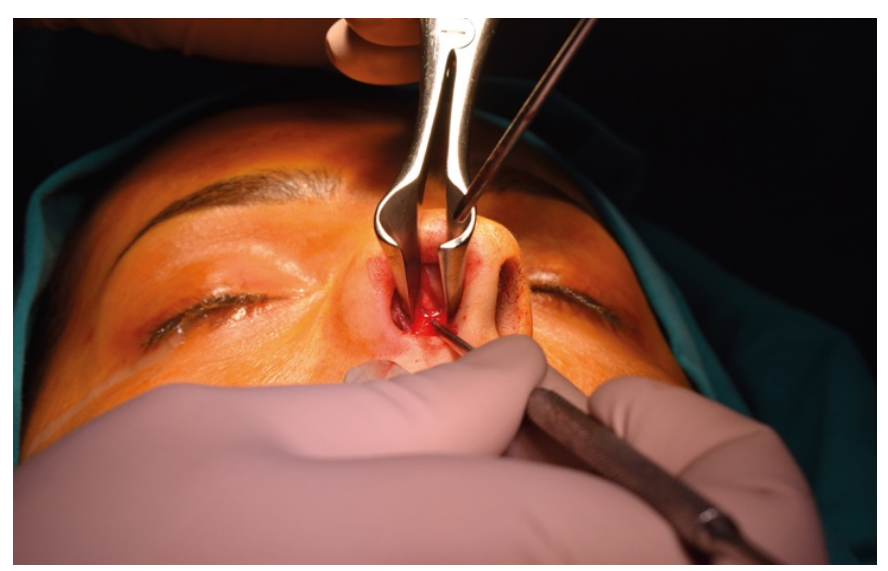

Fig. 5. In closed dorsum-sparing surgery, surgery is initiated by marginal septal incision from the caudal end of the septum. Photographic image of the case process photograph, b-illustration) and (c-written expression). Written expression is given as expressed in figure descriptions. Finally, all the papers were examined and then a questionnaire was completed.

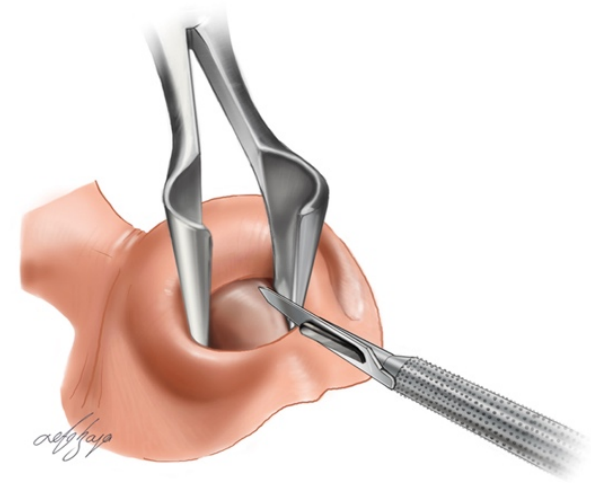

Fig. 2. In closed dorsum-sparing surgery, surgery is initiated by marginal septal incision from the caudal end of the septum. Illustration image as a cross section of the case process

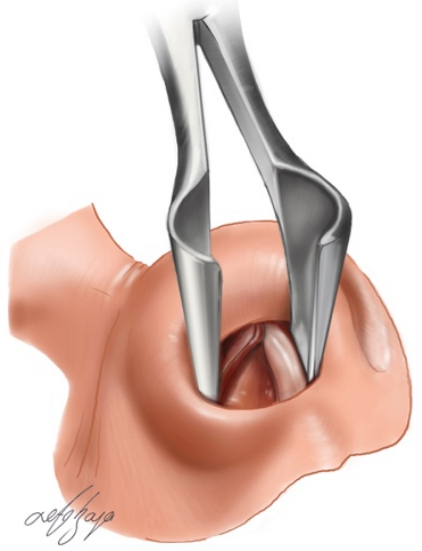

Fig. 4. The incision is remowed from the perichondrium and deepened until cartilage is seen. The nasal speculum is used to visualize the incision site. Illustration image as a cross section of the case process

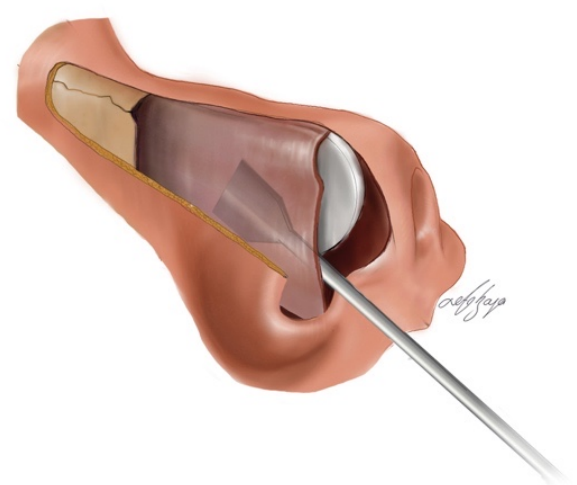

Fig. 6. In closed dorsum-sparing surgery, surgery is initiated by marginal septal incision from the caudal end of the septum. Illustration image as a cross section of the case process 


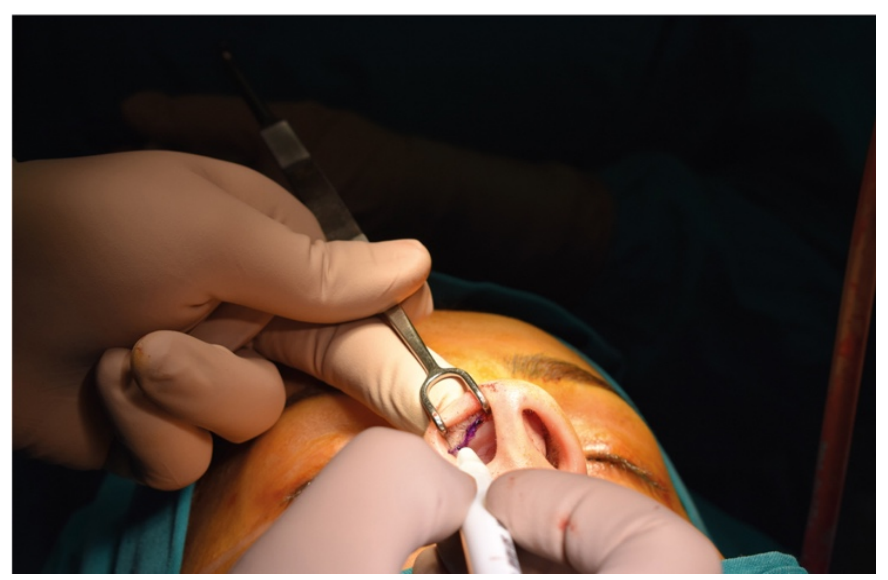

Fig. 7. The incision in the alar wings is made in trans cartilaginous plane. To do this, the incision line is drawn with a surgical pen to leave an approximately 1-2 $\mathrm{mm}$ alar rim graft. Photographic image of the case process

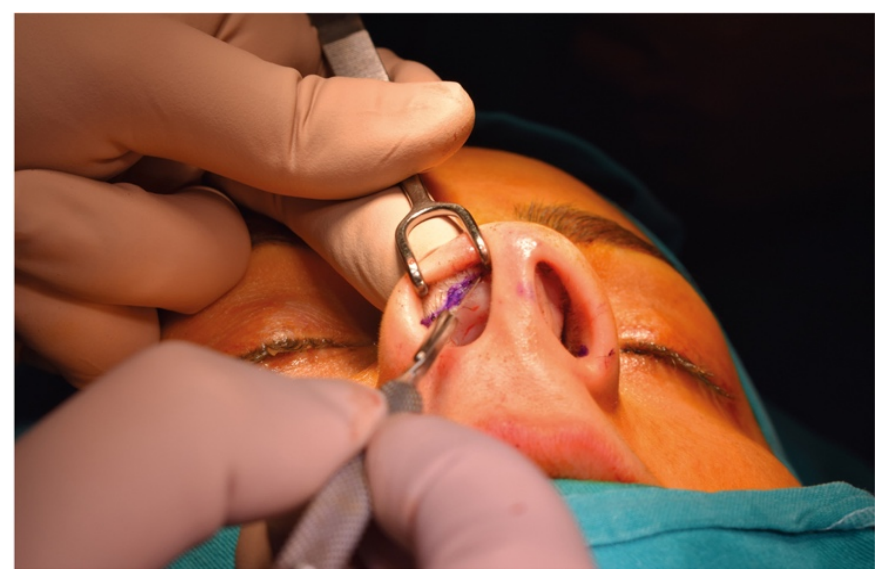

Fig. 9. The skin incision is done with 15 number scalpel. The incision is terminated after passing the cartilage plan. Photographic image of the case process

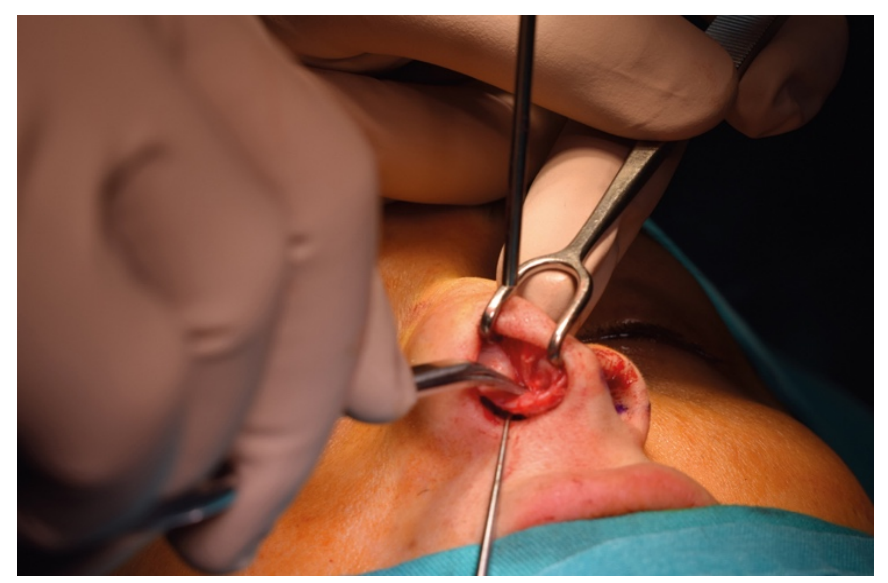

Fig. 11. With the help of elevators, alar cartilages are elevated to the scroll ligament. Photographic image of the case process

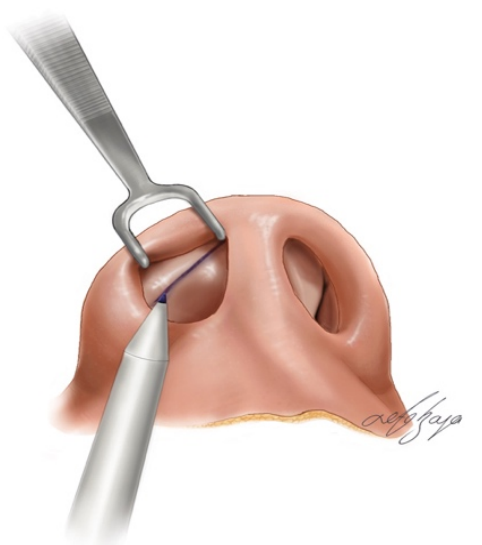

Fig. 8. The incision in the alar wings is made in trans cartilaginous plane. To do this, the incision line is drawn with a surgical pen to leave an approximately 1-2 mm alar rim graft. Illustration image as a cross section of the case process

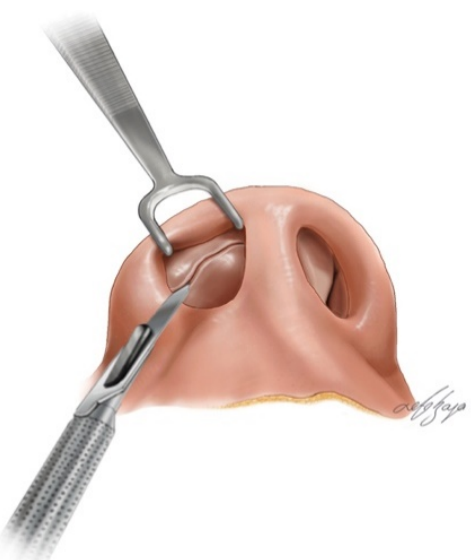

Fig. 10. The skin incision is done with 15 number scalpel. The incision is terminated after passing the cartilage plan. Illustration image as a cross section of the case process

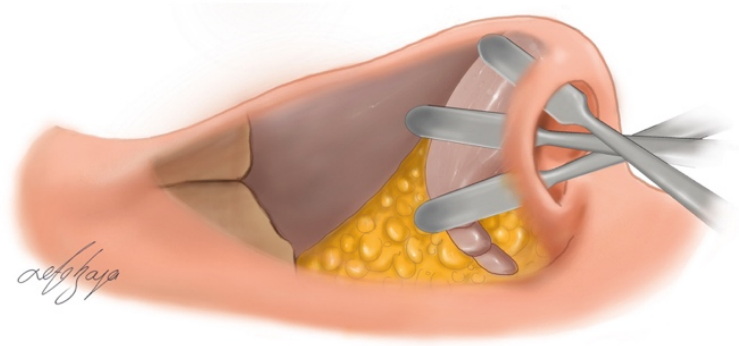

Fig. 12. With the help of elevators, alar cartilages are elevated to the scroll ligament. Illustration image as a cross section of the case process 


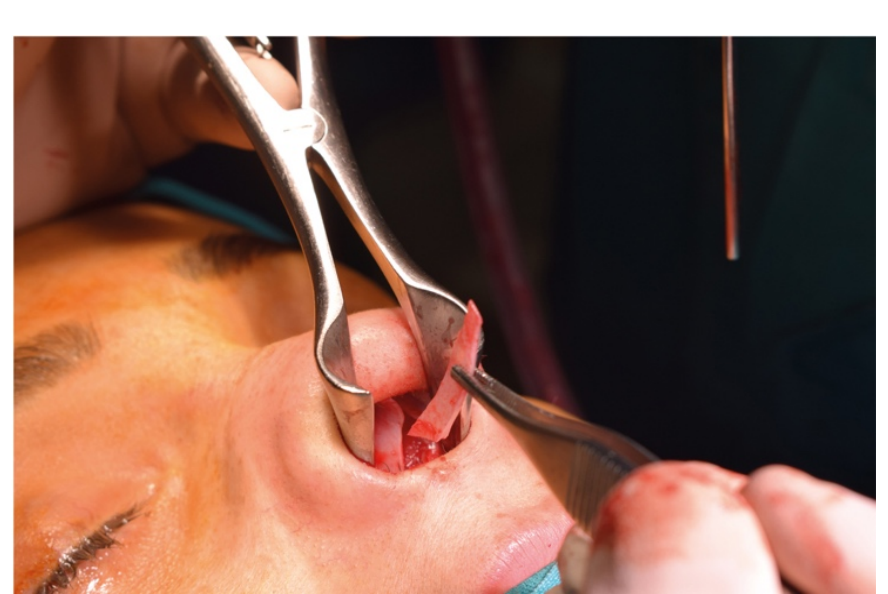

Fig. 13. If necessary, after the elevation, $1-2 \mathrm{~mm}$ cartilage is removed from the posterior part of the septum as vertical strip. Photographic image of the case process

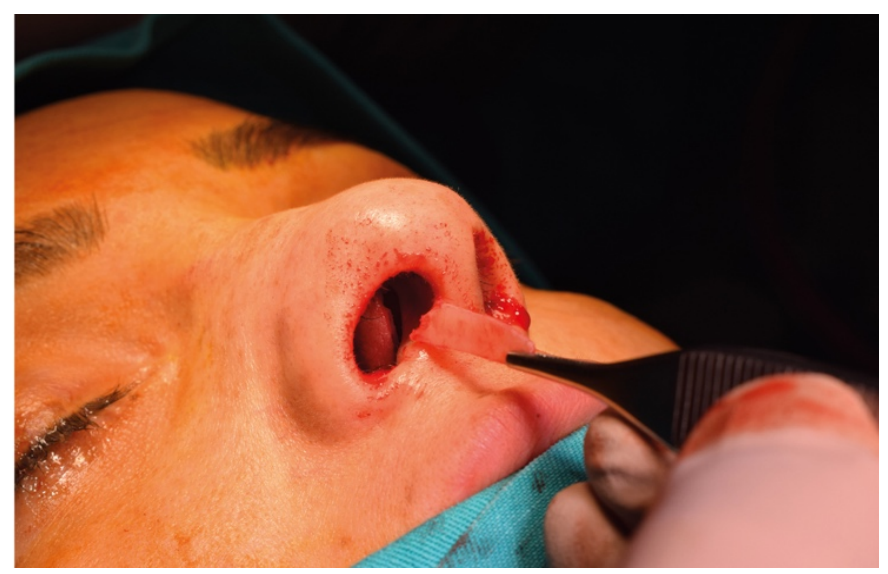

Fig. 15. Excised septum fragment. Photographic image of the case process

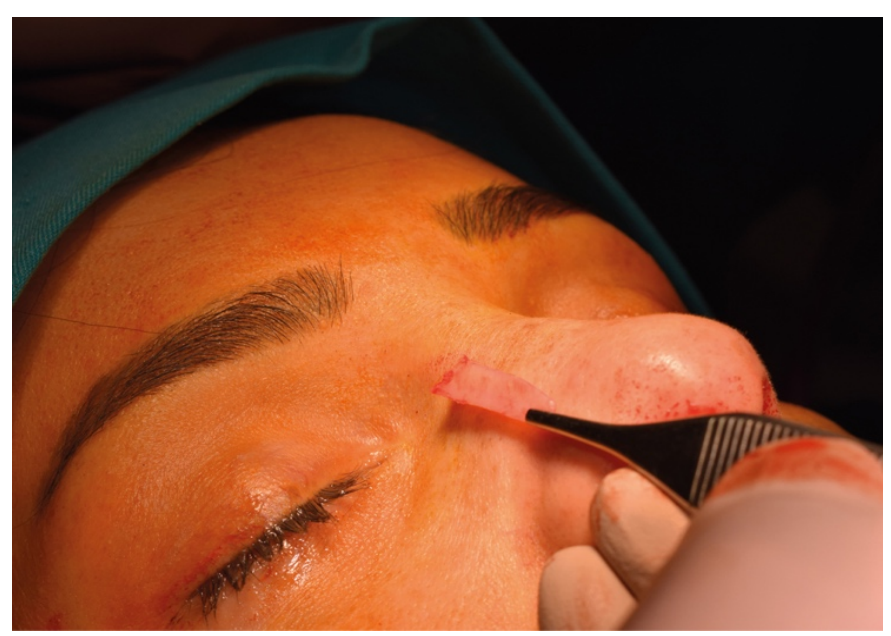

Fig. 17. Excised septum fragment. Photographic image of the case process

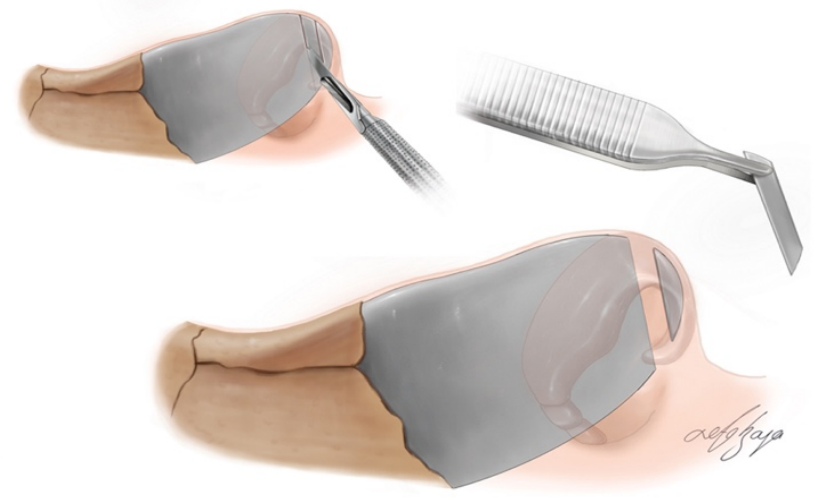

Fig. 14. If necessary, after the elevation, $1-2 \mathrm{~mm}$ cartilage is removed from the posterior part of the septum as vertical strip. Illustration image as a cross section of the case process

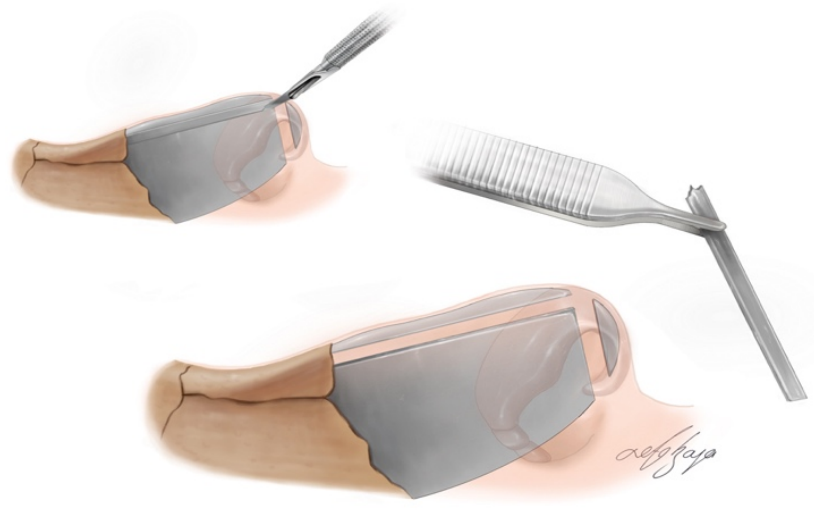

Fig. 16. Excised septum fragment. Illustration image as a cross section of the case process

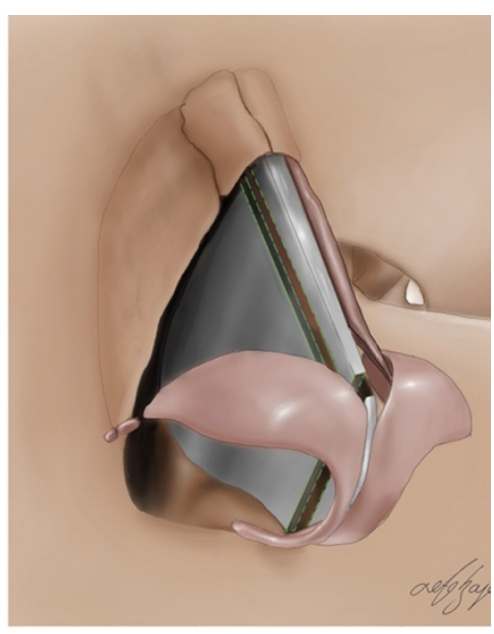

Fig. 18. Excised septum fragment. Illustration image as a cross section of the case process 


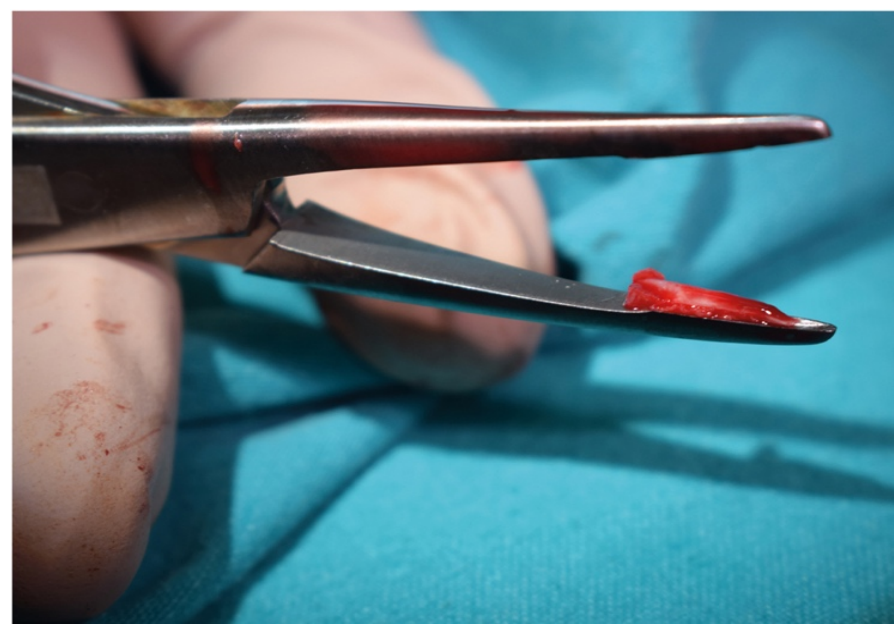

Fig. 19. Once the cartilage is removed, the perpendicular plate of the ethmoid bone is excied using the bone rounger. Photographic image of the case process

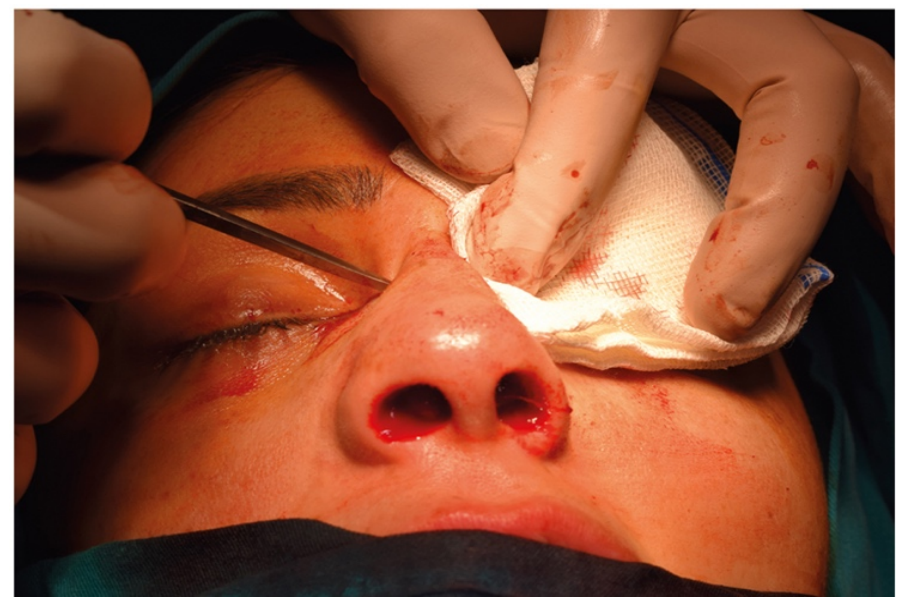

Fig. 21. Lateral and medial osteotomies are performed. Although osteotomes and osteotomies are shown in the figüre, instruments such as microtesters and piezzo may also be used for this purpose

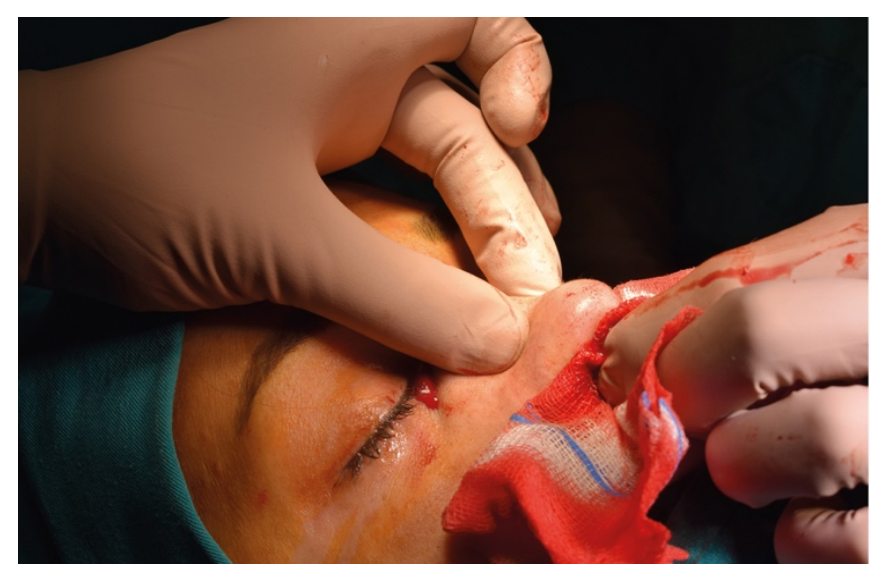

Fig. 23. After osteotomies and cartilage resections are completed, the nasal dorsum is pushed and collapsed and piezzo may also be used for this purpose. Photographic image of the case process
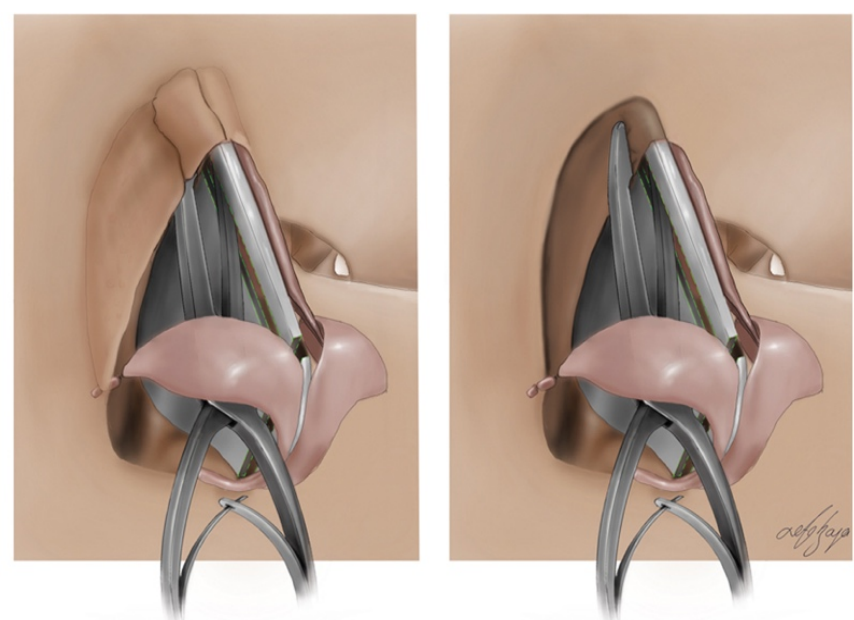

Fig. 20. Once the cartilage is removed, the perpendicular plate of the ethmoid bone is excied using the bone rounger. Illustration image as a cross section of the case process.
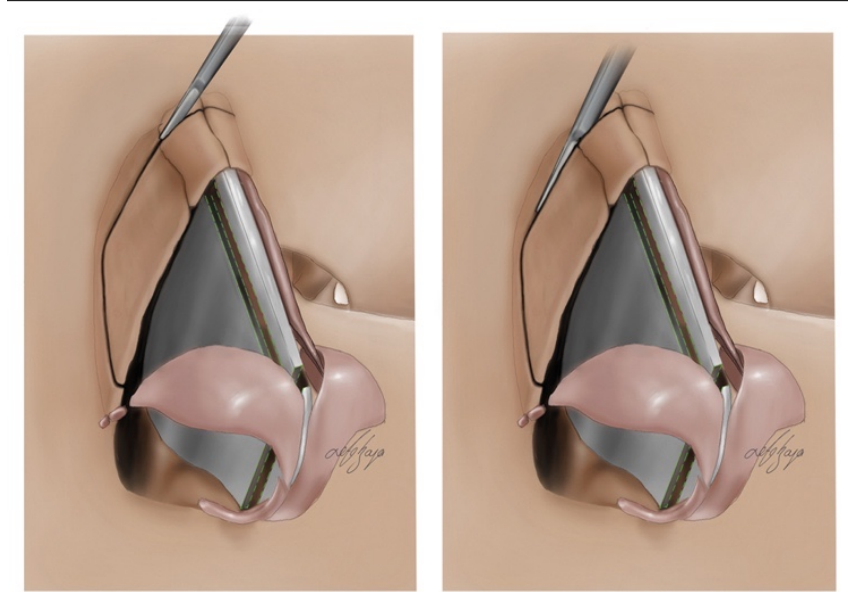

Fig. 22. Lateral and medial osteotomies are performed. Although osteotomes and osteotomies are shown in the figure, instruments such as microtesters and piezzo may also be used for this purpose. Illustration image as a cross section of the case process

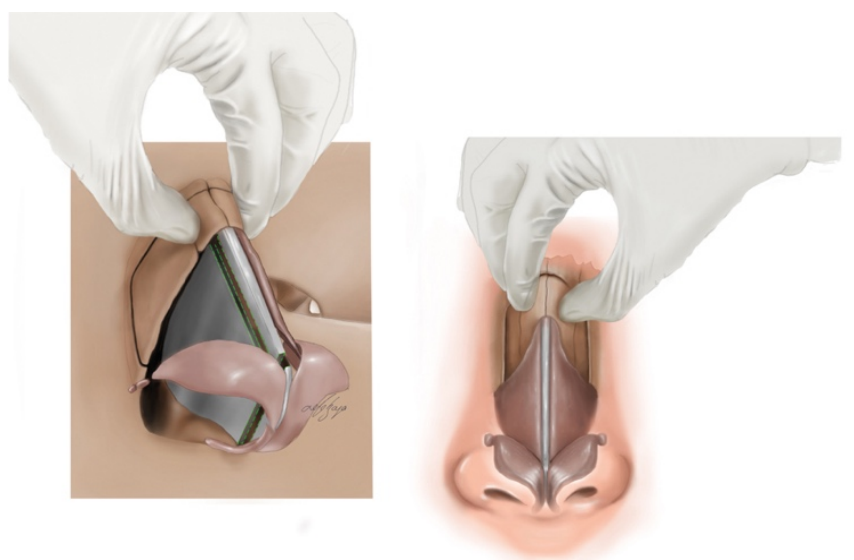

Fig. 24. After osteotomies and cartilage resections are completed, the nasal dorsum is pushed and collapsed and piezzo may also be used for this purpose. Illustration image as a cross section of the case process 
Kaya et al. / J Exp Clin Med

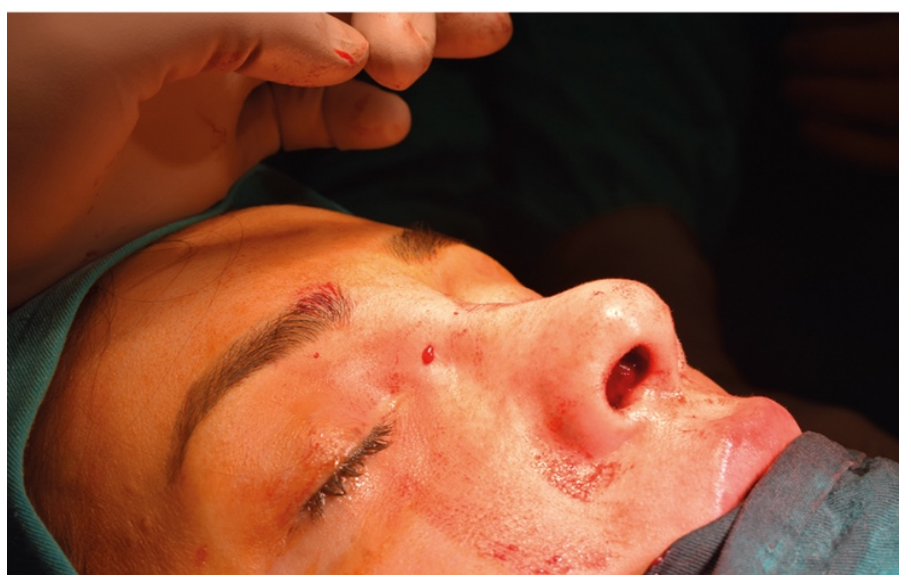

Fig. 25. Schematic view of the pushing of the nasal dorsum. Photographic image of the case process

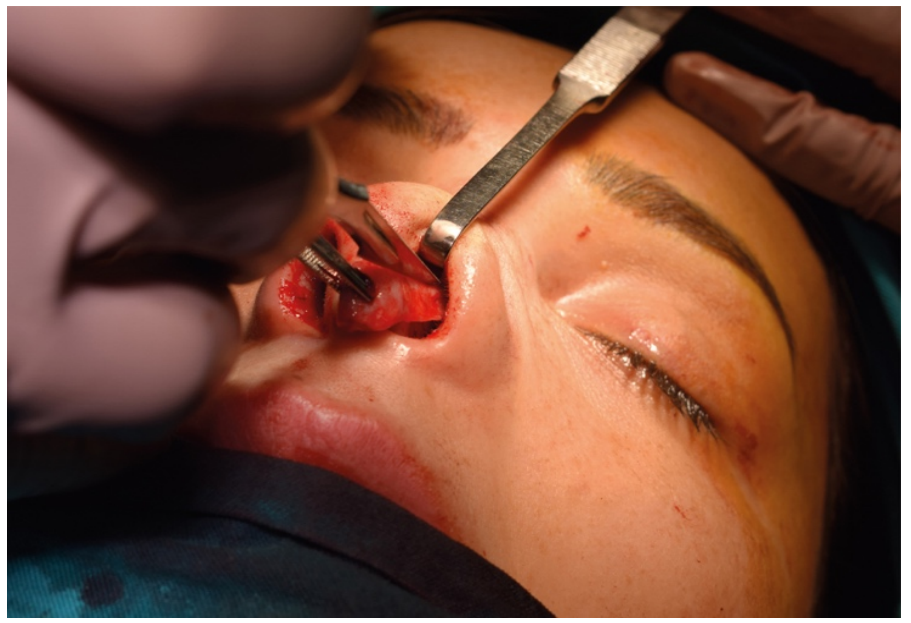

Fig. 27. Resection is performed with a scalpel and the remowed part is being seen. Photographic image of the case process

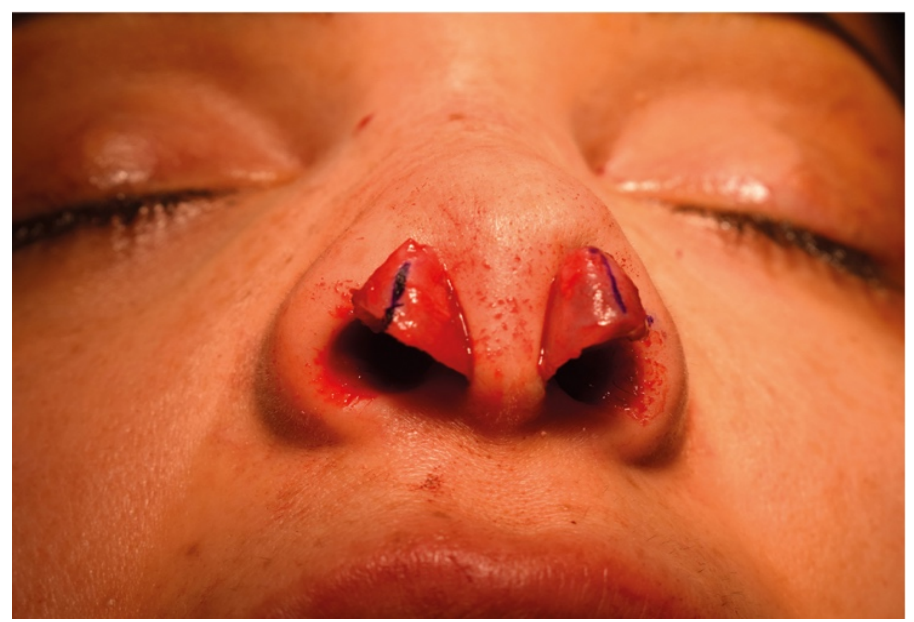

Fig. 29. The DOM portions of the alar cartilages are marked. Photographic image of the case process
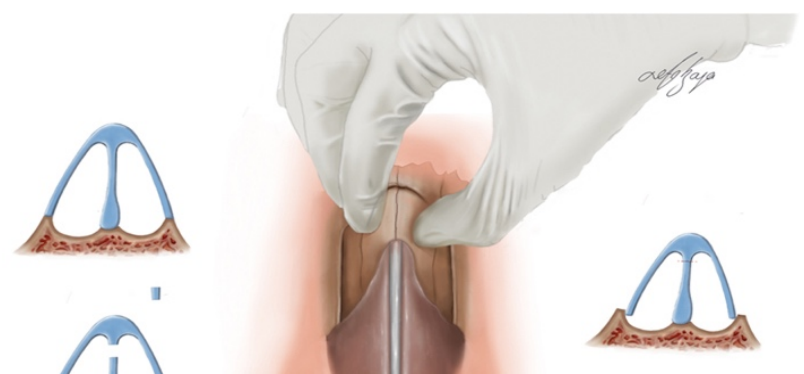

Fig. 26. Schematic view of the pushing of the nasal dorsum. Illustration image as a cross section of the case process
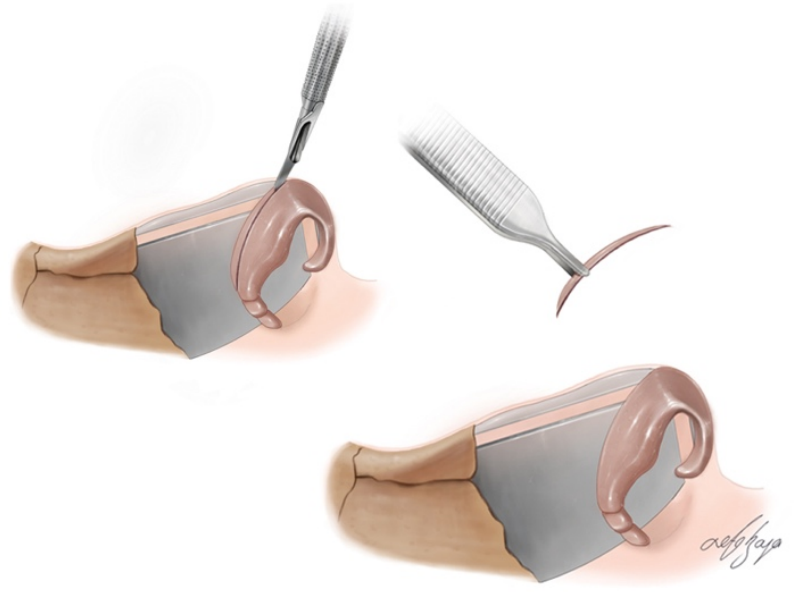

Fig. 28. Resection is performed with a scalpel and the remowed part is being seen. Illustration image as a cross section of the case process

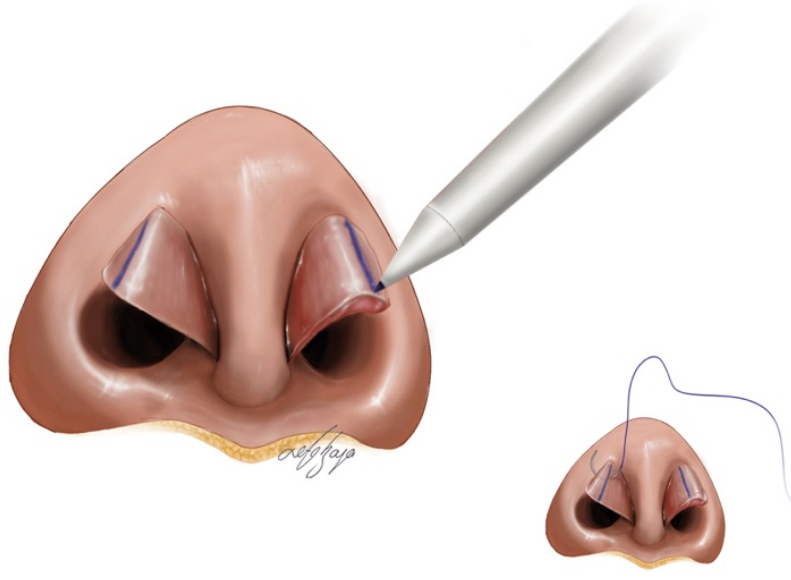

Fig. 30. The DOM portions of the alar cartilages are marked. Illustration image as a cross section of the case process 


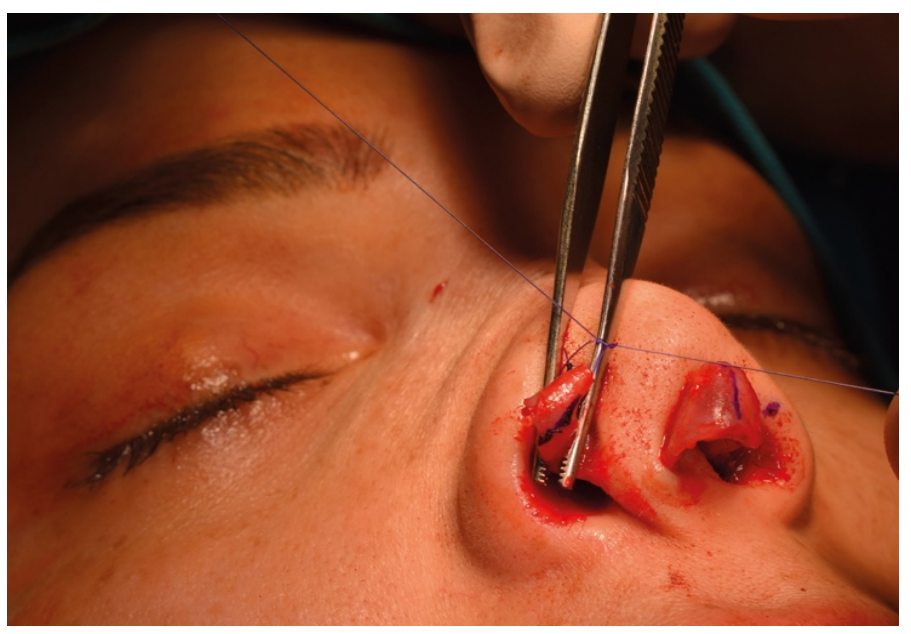

Fig. 31. Marking the DOM parts of the alar cartilages is being seen. Photographic image of the case process

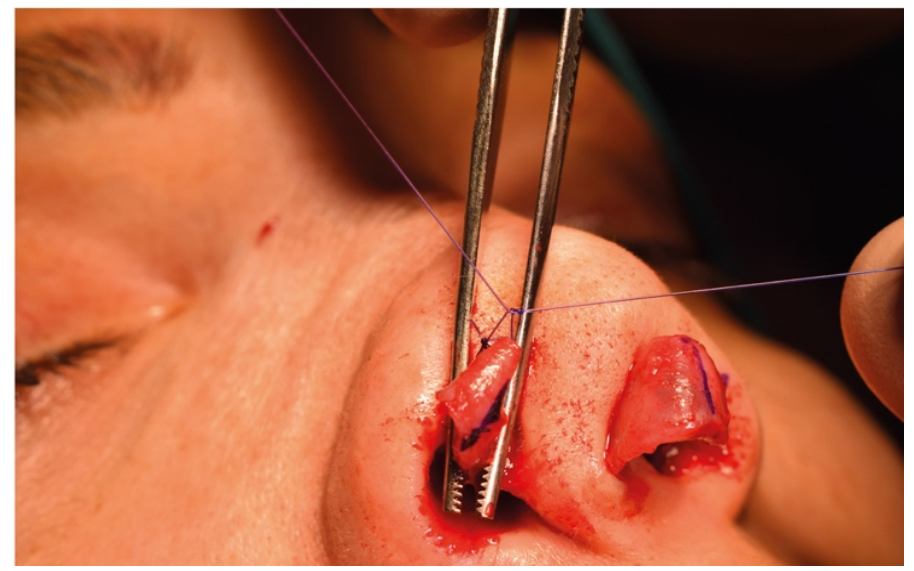

Fig. 33. DOM stealing sutures according to the need of the case after marking the dom portions of the alar cartilages. Photographic image of the case process

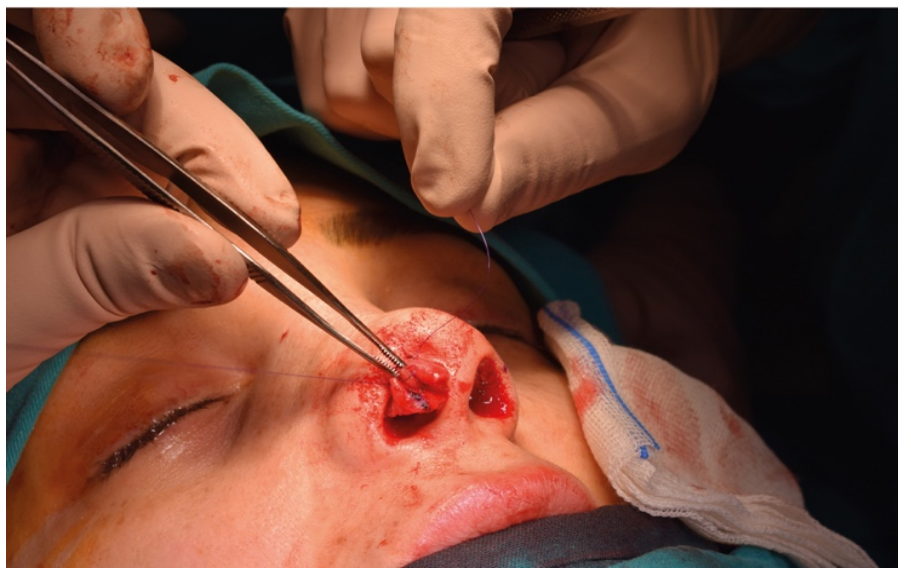

Fig. 35. It is sutured with at least two points (one of which is the DOM region) with 5/0 PDS. Photographic image of the case process

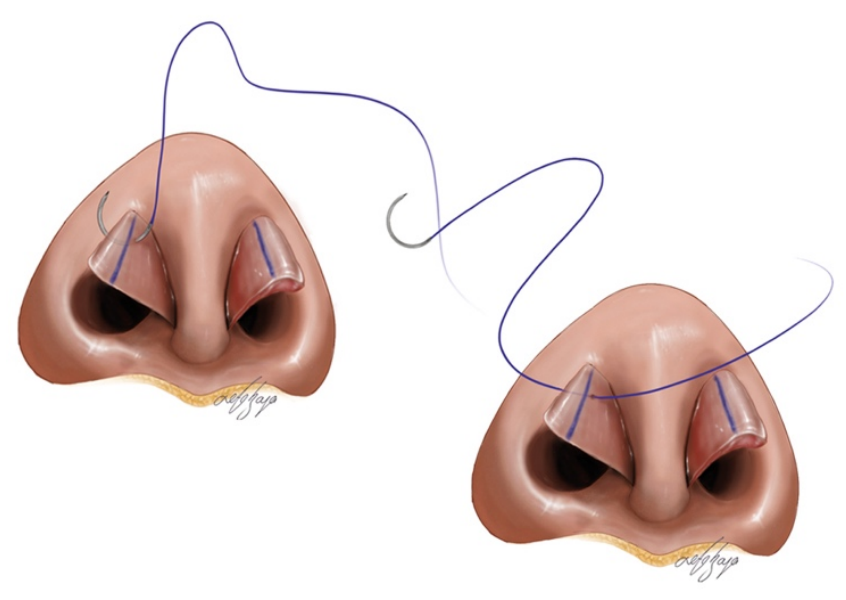

Fig. 32. Marking the DOM parts of the alar cartilages is being seen. Illustration image as a cross section of the case process
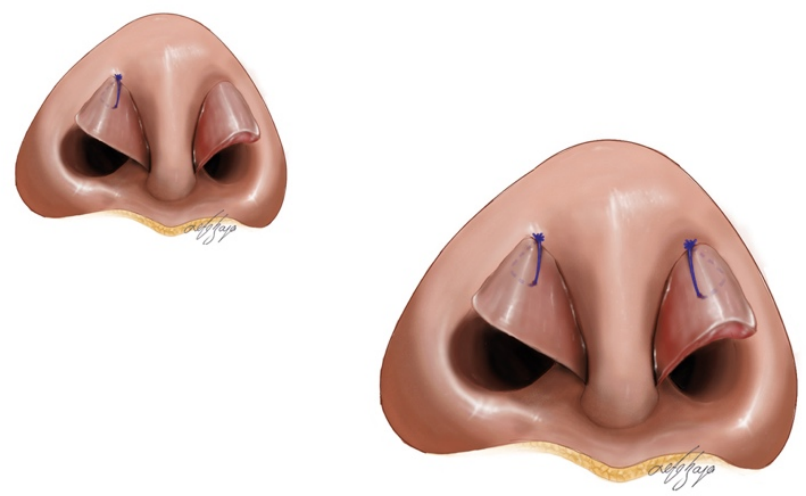

Fig. 34. DOM stealing sutures according to the need of the case after marking the dom portions of the alar cartilages. Illustration image as a cross section of the case process

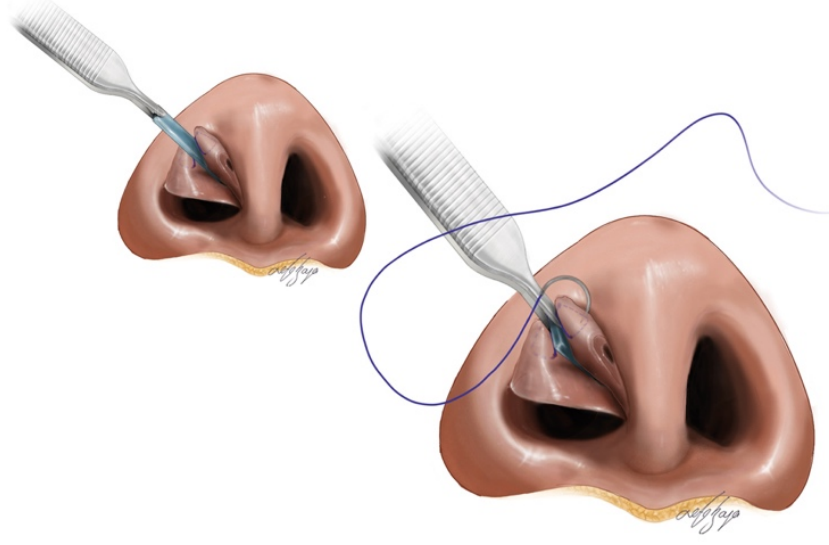

Fig. 36. It is sutured with at least two points (one of which is the DOM region) with 5/0 PDS. Illustration image as a cross section of the case process 


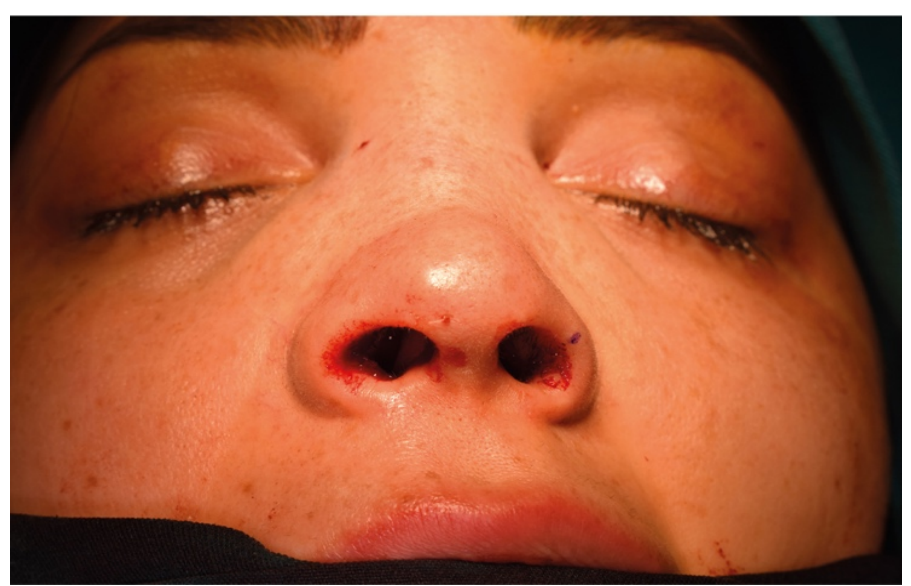

Fig. 37. Stabilization of columellar strut to alar cartilages. Photographic image of the case process

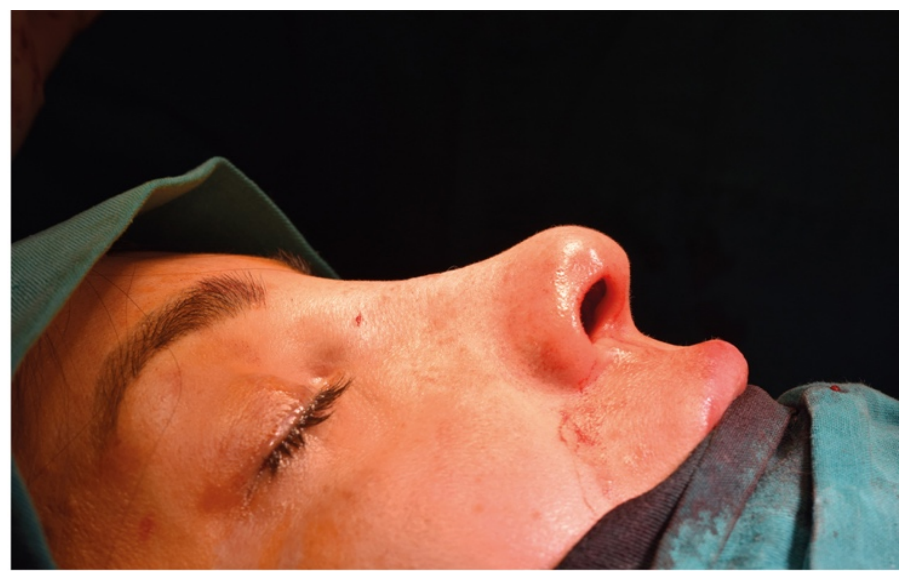

Fig. 39. The appearance of sutures after surgery. Photographic image of the case process

\section{Results}

The study population of 107 participants comprised resident doctors, associate professors, assistant professors, professors, and medical students of Ondokuz Mayis University, Hitit University and İstanbul Medeniyet University. Thus, the population included both surgery experts and medical students, as 71 specialists from the relevant areas and 36 medical students (Table 1).

Table 1. Distribution of the study participants according to specialty, title and number

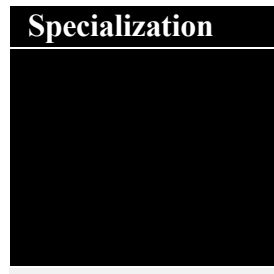

Ear, Nose and

Throat Surgery

Aesthetic,

Plastic and

Reconstructive

Surgery

Medical

Students

Total nd

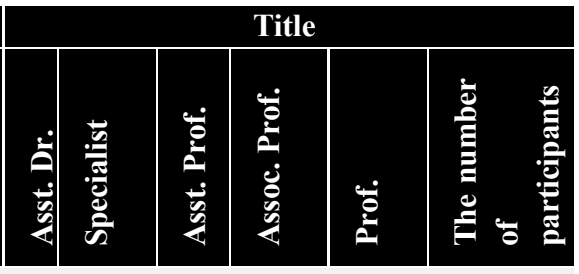

60

$\begin{array}{llllll}1 & 4 & 0 & 6 & 0 & 11\end{array}$

$200 \quad 0 \quad 0 \quad 36$

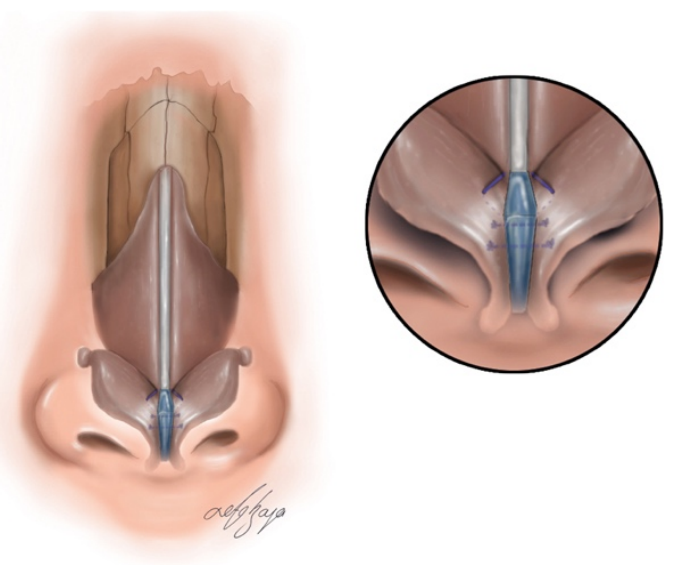

Fig. 38. Stabilization of columellar strut to alar cartilages. Illustration image as a cross section of the case process

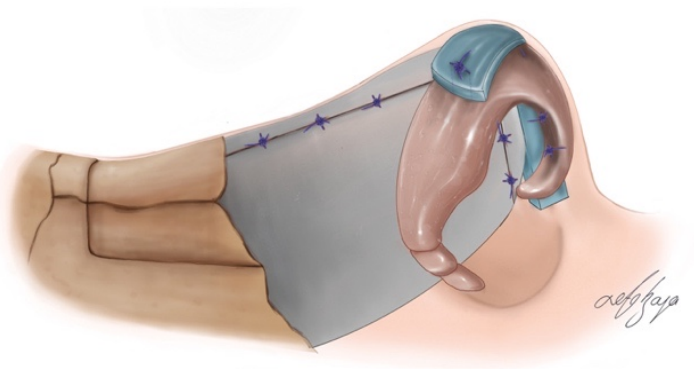

Fig. 40. The appearance of sutures after surgery. Illustration image as a cross section of the case process

The question, "Do illustrations of the surgical procedures express the subject better than photography and written expression?" had a response of "agree" by 80 (78\%) respondents (Table 2). To the question "Do photographs of the surgical procedures express the subject better than illustrations and written expressions?", the response of "agree" was given by $23(21.5 \%)$ respondents and "disagree" by $51(30.8 \%)$ (Table 2). To the question of "Do written expressions of the surgical procedures express the subject better than photography and illustrations?" 18 (16.8\%) respondents answered "agree", 27 (25.2\%) were "undecided" and $62(57.9 \%)$ gave the response of "disagree" (Table 2). The preference for the use of visual and written forms together was expressed by most of the specialists and students with $96(89.7 \%)$ respondents stating "agree", 6 (4.7\%) were "undecided" and $5(5.6 \%)$ disagreed (Table 2). The other questions and responses are shown in Table 2 and Table 3.

\section{Discussion}

When the development process of visual elements is examined, it can be seen to fulfill the task of transferring knowledge along the communication pathway from past to present. Medicine is one of the fields in which images are used or should be used as messages. Visual material may be medical illustrations or surgical photographs, and in both 
eastern and western cultures, medical illustrations have been used since prehistoric times. An increased need and demand for medical illustrations in the field of medicine led to the opening of schools providing medical illustration education. These illustrations have been among the most important sources for describing and archiving surgical techniques and findings, and diagnostic and treatment methods and for the transfer of this knowledge to the next generation.

Table 2. Responses to the questions

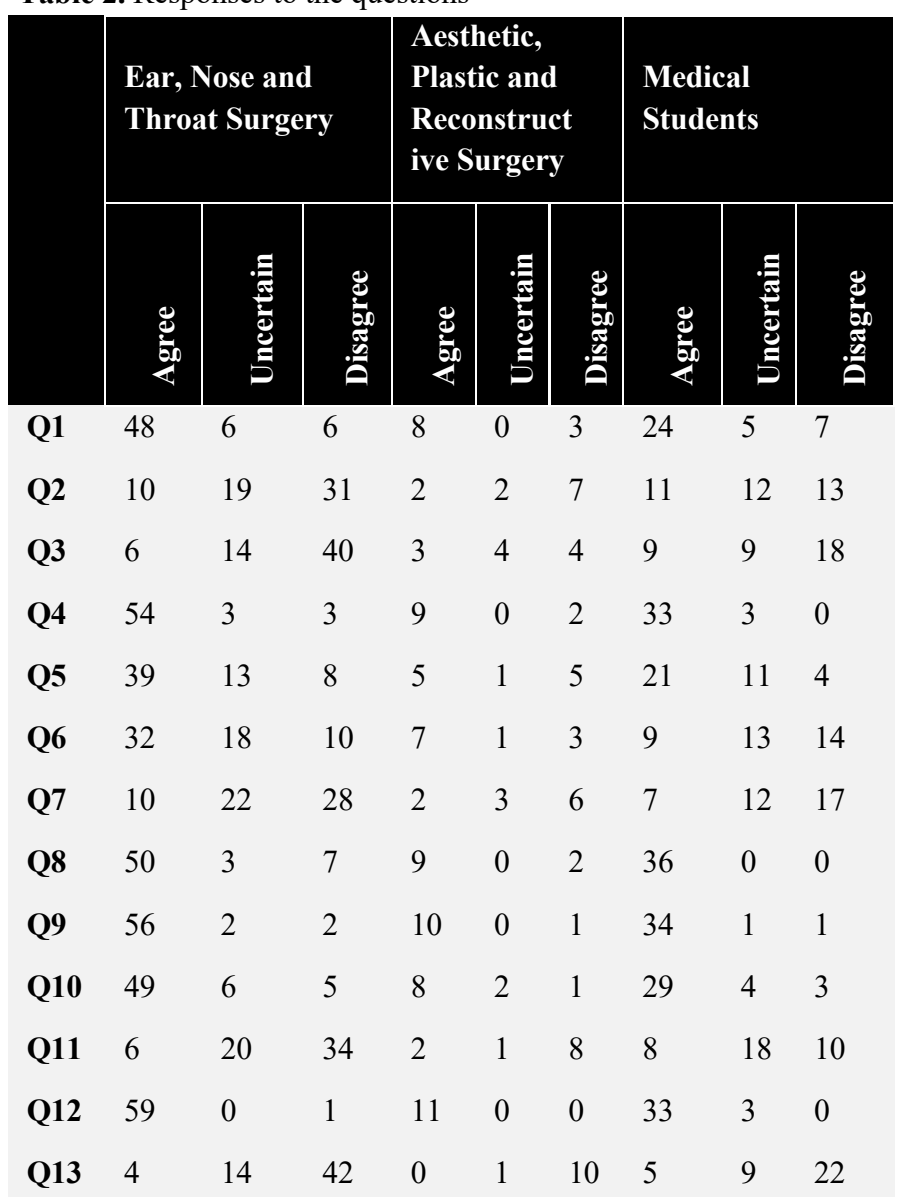

Q1. Illustrations of the surgical procedures express the subject better than photography and written text

Q2. Photographs of the surgical procedures express the subject better than illustrations and written text

Q3. Surgical procedures express the subject better than illustrations and photographs

Q4. Illustrations, photographs, and written text of the surgical procedures should be used together

Q5. The use of illustrations and written text express the subject in the best way

Q6. Illustrations express the subject in detail

Q7. Photographs express the subject in detail

Q8. Illustrations are not sufficient to explain the surgical subject

Q9. Written text is not sufficient to explain the surgical subject

Q10. Illustrations and photography should be used together to explain the surgical subject

Q11. Photographs can explain the surgical subject with the required clarity

Q12. The use of illustrations is important in rhinoplasty education and academic publications

Q13. Photographs are sufficient in rhinoplasty education
Table 3. Responses to the question of the use of which of these forms of expression is important in education

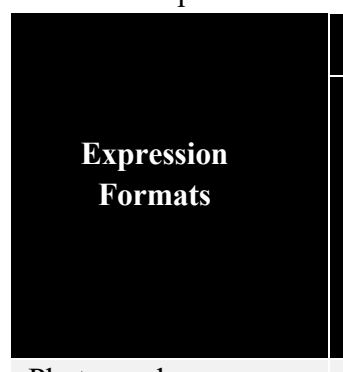

Photograph

Illustration

Written Expression

Writing and

Illustration

Writing

Photograph

Photography,

Illustration and

Written Expression

Total

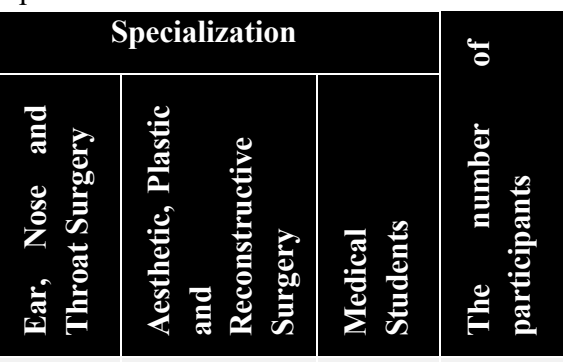

0

5

0

0

0

0

5

0

82

107
According to recent literature, multimedia teaching is more effective than traditional teaching (Motsumi et al., 2019). Studies have demonstrated that visual-based surgical skills training improves the acquisition of surgical skills when combined with standard verbal feedback, compared with standard verbal feedback alone (Farquharson et al., 2013). Visual-based teaching reduces the amount of verbal input needed during the demonstration of surgical skills and reduces learning time. Therefore, the use of medical illustrations on educational platforms, which is an important part of the medical field, can be said to make a positive contribution to the quality of education.

As an interdisciplinary field, medical illustrations can be used in medicine, especially in surgical cases, as illustrations only or together with other forms of expression such as photography and written text. In this study, the field of surgery was limited to nasal surgery to demonstrate competence and the utility of illustrations, photography and written text. The visual and written expression forms were compared and the power to express the subject in terms of surgical training was investigated.

In the opinions stated according to their field of expertise, the ENT surgeons stated that the photographs alone were not sufficient because the frame boundaries could not be well distinguished, and that the use of illustrations together with photographs would be important in resident and student education. The need for photography and recording was considered important to be able to use the procedures performed during surgery for scientific purposes. An ENT Professor Doctor stated that the use of $3 \mathrm{D}$ visuals in presentations related to dynamic medical cases and the use of 
medical illustrations in the presentations about static cases could provide a better qualified presentation or education / training and that the photographs alone could not be understood sufficiently even by experts in the field. Experts preferred illustrations to see the surgical cases in more visual detail. The students stated that the use of illustrations with photographs and written text together was more memorable, as there are cases in which the photographs are insufficient by themselves and combined use was more efficient in describing three dimensions. It was evident that the medical illustrations may be more sufficient in comparison to photography and written text but they could not provide the desired quality level alone. Therefore, it was concluded that illustrations alone are not sufficient to describe the surgical procedures and should be used together with other forms of expression. Of the 60 respondents from the ENT specialism area, 43 considered it more important to use illustrative, photographic and written expressions together for informational purposes. Title-related variables were not found in the participants' statements.

Aesthetics, Plastic and Reconstructive Surgery specialists showed similar results in their responses. In this area of expertise, although not variable, 9 of 11 participants found it important to use illustrative, photographic and written expressions together for information purposes. The responses of the non-specialist medical faculty students to the scales varied from those of the field specialists. Although it was seen that illustrations expressed the subject better than photographs and written text, an indecisive attitude was mostly taken. It is clear that neither illustrations nor photographic images are sufficient to demonstrate surgical procedures. While the majority of the respondents accepted the importance of illustrations in rhinoplasty education and scientific publications, photographic images were also accepted as important, but were not considered to be as effective as illustrations. The view that a high-quality education / training environment will be provided with the use of visual and written expression forms in rhinoplasty education has not changed. When the results of the analysis were examined, no difference was observed in the responses of the experts. However, indecisiveness and differences were observed in the responses of non-experts. Nevertheless, all participants stated that it is necessary to use illustrations, photographs and written text together in appropriate situations. Consequently, it can be seen that medical illustrations have been used as a necessity in the medical field since the beginning, that they developed parallel to the text and embodied the writing and give meaning to the photographic images. Therefore, it is important that standardized high-quality illustrations are produced by experts in the field. It is a common opinion that illustrations are strong in expression but not sufficient. This was reported in research findings at the University of Texas that when the time factor is kept static, individuals can remember $50 \%$ of what they see and hear, $30 \%$ of what they see and $10 \%$ of what they read (Kinder, 1973). Recent studies have shown the benefits of using visual tools (photographs, illustrations, 3D visuals etc.) in the learning process, specifically converting cognitive input into long-term memory, indicative of learning (Mota et al., 2018). Educational research based on visual learning has shown that this can significantly improve surgical performance. Visual-based training both significantly improves surgical education and can be seen as a reasonable additional tool to be included in surgical education curricula because it leads to improvement in surgical performance (Pape-Kohler et al., 2013). When medical publications are examined, it can be seen that visuals, diagrams, graphics and photographs are used together with written text. These commonly used visual materials contribute to visual perception due to the creation and reinforcement of a visual image. Visual perception is the most effective of the human perception channels. A phenomenon that can be described only by several pages of writing is more easily expressed by a single illustration (Mavroudis et al., 2020). However, the requirement for living tissue to be seen in many cases necessitates supporting the illustration with photographs.

From the findings of this study, it was concluded that illustrations alone are not sufficient and should be supported with photographs. With this reference point, it may be suggested to establish and expand the institutions and organizations serving in the field of clinical and medical photography with examples in various countries. The use of 3D models in the medical and surgical field can create a more interactive educational channel. Illustrations are generally used in crochet training publications. Creating a resource by visualizing new surgical cases can be considered both in terms of education and archives. Future studies should focus on better characterization of the link between the use of surgical visual elements and overall surgical skills. In addition, future studies should give priority to the integration of standardized assessment tools which facilitate the surgical performance and skill of students and residents.

In this study, it has been shown that visual-based education (photographs, illustrations, 3D visuals and the like) can provide substantial benefits in surgical education by reducing the significant barriers that students and residents face in practice. The findings of a systematic review provided fair to good quality studies, which demonstrated significant gains in knowledge compared with traditional teaching (Akgül et al., 2018). Findings of this research has revealed that illustrations are more effective than photographs, but the illustrations should be used together with other forms of visual and written expression. Such an expression is more effective and preferred in both educational and academic publications.

In conclusion, a quality visual-based surgical education method is effective according to the recent findings in the 
literature. Visual elements should supplement the standard techniques such as text in surgical education.

\section{Conflict of interest}

None to declare.

\section{Acknowledgments}

None to declare.

\section{References}

1. Akgül, A., Kuş, G., Mustafaoğlu, R., Karaborklu, A.S., 2018. Is Video-Based education an effective method in surgical education? A systematic review. J. Surg. Educ. 75, 1.

2. Crawshaw, B.P., Steele, S.R., Lee, E.C., Delaney, C.P., Mustain, W.C., Russ, A.J., 2016. Failing to prepare is preparing to fail: A single-blinded, randomized controlled trial to determine the impact of a preoperative instructional video on the ability of residents to perform laparoscopic right colectomy. Dis. Colon. Rectum. 59, 32.

3. Farquharson, A.L., Cresswell, A.C., Beard, J.D., Chan, P., 2013. Randomized trial of the effect of video feedback on the acquisition of surgical skills. Bri. J. Surg. 100, 1452.
4. Kinder, J.S., 1973. Using instructional media. New York: Litton Educational Publishing Inc.

5. Mavroudis, C., Lees, G.P., Idriss, R., 2020. Medical illustration in the era of cardiac surgery. World J. Pediat. Congenital Heart Surg. 11, 209.

6. Motsumi, M.J., Bedada, A.G., Ayane, G., 2019. The role of Moodle-based surgical skills illustrations using 3D animation in undergraduate training. Afr. J. Health Prof. Educ. 11, 149.

7. Mota, P., Nuno, C., Carvalho-Dias, E., Costa, M.J., CorreiaPinto, J., Lima, E., 2018. Video-Based surgical learning: Improving trainee educationand preparation for surgery. J. Surg. Educ. 75, 1.

8. Pape-Koehler, C., Immenroth, M., Sauerland, S., Lefering, R., Lindlohr, C., Toaspern, J., 2013. Multimedia-based training on Internet platforms improves surgical performance: A randomized controlled trial. Surg. Endosc. 27, 1746.

9. Songur, A., 2016. Tıp eğitimindeki çıkmazlardan biri: Fakülte yönetimi ile hastane yönetimi ikilemi. Tıp Eğitimi Dünyası. May-Aug: 46: (14 screens). 